\title{
Liricidad y toque de arte para la producción del cono- cimiento estético de enfermería - una reflexión poética inspirada en la Teoría de la Complejidad
}

\section{Liricidade e toque de arte para a produção do conhecimento estético de enfermagem - uma reflexão poética inspirada na Teoria da Complexidade*}

\section{Lyricism and a touch of art for the aesthetic of nursing knowledge production - a poetic reflection inspired by the Theory of Complexity}

Onã Silva ${ }^{1}$, Elioenai Dornelles Alves ${ }^{2}$ y Maria Cristina Soares Rodrigues ${ }^{3}$

${ }^{1}$ Enfermeira. Mestre em Educação. Doutoranda do Programa de Pós-Graduação em Enfermagem/UnB. Pesquisadora de Grupos de Pesquisas Criatividade e Aprendizagem Lúdica/UnB/CNPq. Graduada em Artes Cênicas. Escritora. Poetisa do Cuidar ${ }^{2}$ Enfermeiro, Doutor e Livre Docente. Professor Titular aposentado e Pesquisador Sênior da Universidade de Brasília, Programa de Pós-Graduação em Enfermagem da UnB. Líder do Núcleo de estudos em educação, promoção da saúde e projetos inclusivosCEAM/UnB, Pesquisador do CNPq.

${ }^{3}$ Doutora em Ciências da Saúde. Professora Associada da Faculdade de Ciências da Saúde, Departamento de Enfermagem e do PPGEnf da UnB. Líder do Laboratório de Estudos e Pesquisas Multidisciplinares em Segurança do Paciente.

Cómo citar este artículo en edición digital: Silva, O; Alves, E.D. y Rodrigues, Ma C. S. (2014) Liricidad y toque de arte para la producción del conocimiento estético de enfermería - una reflexión poética inspirada en la Teoría de la Complejidad. Cultura de los Cuidados (Edición digital) 18, 39. Disponible en: http://dx.doi.org/10.7184/cuid.2014.39.03>

Correspondencia: QE 34, Conjunto R, Casa 36 - Guará II - Distrito Federal-Brasil- CEP 71065-182

Correo electrónico: onatil@gmail.com

Recibido: 07/01/2014; Aceptado: 16/03/201

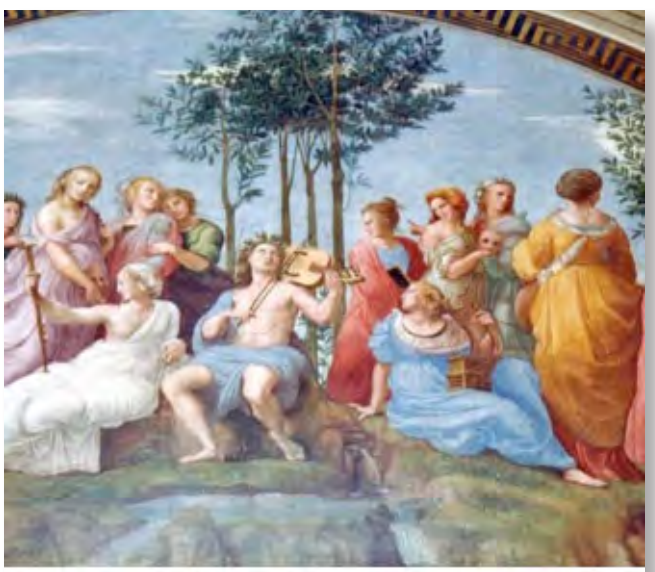

Musas - Parnaso - Rafael

\section{ABSTRACT}

The inspiration for this study originated from the absence of reference in the theme and the troubling questions that echoed in the chords of the author's lyric self: Is poetry important for nursing referred to as science and art? Considering the full time care,is there place for the aesthetic knowledge, in spite of the same being so little searched? The objective was to reflect and analyze the importance of the poetic text for the aesthetic of nursing knowledge, using as analysis tool the poem On the poetic clay, my reflections on the science care written by the author-nurse, based on the Theory of Complexity. The poem analyzed addresses various dimensions of human complexity necessary for the care of themselves, of others and of the populations who revitalize the inexhaustible aesthetic source and gener-

* Este trabalho é parte integrante e compilado da Tese de Doutorado "As ondas revitalizadoras da criatividade no ensino de enfermagem: estudo comparativo e multifatorial do perfil criativo dos atores educacionais", apresentada ao Programa de Pósgraduação em Enfermagem, Universidade de Brasília. A Tese é defendida pela $1^{a}$ autora, sob a orientação do $2^{\circ}$ autor e coorientação da $3^{a}$ autora. 
ating health. Poetic elements are fundamental for reflection, production and disclosure of knowledge of nursing aesthetic being essential and inseparable em every action of taking care.

Keywords: Nursing, Aesthetic knowledge, Poetry, Care, Theory of Complexity

\section{RESUMEN}

La inspiración para este estudio se originó de la ausencia de referencial en la temática y de preguntas inquietantes que resonaron en los acordes del yo lírico de la autora: ¿la poesía tiene importancia para la enfermería referenciada como ciencia y arte? Considerando el cuidado integral, ¿hay lugar para el conocimiento estético, a despecho de lo mismo ser tan poco investigado? Se objetivó reflejar y analizar la importancia del texto poético para producción del conocimiento estético de enfermería, utilizando como instrumento de análisis el poema En la arcilla poética, mis reflexiones sobre la ciencia de los cuidados escrito por la autora-enfermera, basándose en la Teoría de la Complexidad. El poema analizado aborda varias dimensiones de la complexidad humana necesarias para el cuidado de sí, del otro y de las poblaciones que se revitalizan en la inagotable fuente estética y generadora de la salud. Elementos poéticos son fundamentales para reflexión, producción y divulgación del saber estético de la enfermería, siendo esenciales e indisociables en toda acción de cuidar.

Palabras-clave: Enfermería, Saber estético, Poesía, Cuidados, Teoría de la Complexidad

\section{RESUMO}

A inspiração para este estudo originou-se da ausência de referencial na temática e de perguntas inquietantes que ecoaram nos acordes do eu-lírico da autora: a poesia tem importância para a enfermagem referencia- da como ciência e arte? Considerando o cuidado integral, há lugar para o conhecimento estético, a despeito de o mesmo ser tão pouco pesquisado? Objetivou-se refletir e analisar a importância do texto poético para produção do conhecimento estético de enfermagem, utilizando como instrumento de análise o poema $\mathrm{Na}$ argila poética, as minhas reflexões sobre a ciência dos cuidados, escrito pela autora-enfermeira, baseado na Teoria da Complexidade. O poema analisado aborda várias dimensões da complexidade humana necessárias para o cuidado de si, do outro e das populações que se revitalizam na inesgotável fonte estética e geradora da saúde. Elementos poéticos são fundamentais para reflexão, produção e divulgação do saber estético da enfermagem, sendo essenciais e indissociáveis em toda ação cuidativa.

Palavras-chave: Enfermagem, Saber estético, Poesia, Cuidados, Teoria da Complexidade.

\section{INTRODUÇÃO}

O som do eu-lírico começou a despertar esta autora naquele ambiente de dialogicidade na primavera de 2011. A princípio, não havia motivo pessoal que favorecesse a inspiração e o despertar da liricidade poética, visto que a autora passava por momento particular de enfermidade, mas ela lembrou-se da natureza fênix dos poetas: Eu canto porque o instante existe / e a minha vida está completa. / Não sou alegre nem sou triste: sou poeta (Meireles,1973,p.5).

Primeiro, a dor física lancinava os ossos da autora, não permitindo inspiração nem o exercício de poetar. Mas os ouvidos poéticos captaram alguns acordes melodiosos, depois o esboço de versos até o êxtase de uma fruição de estrofes e poesias completamente produzidas - inspiradas na história da ciência, produção 
de saberes e conceitos estruturados sobre cuidado. Este exercício que misturou ciência, sonho, sensibilidade, está incluído no paradigma vigente de pensar a enfermagem, vislumbrando o estímulo e a produção do conhecimento estético da área.

Para a produção da ciência estética, a fruição poética que envolveu esta autora foi relacionada aos seus conhecimentos e experiência como enfermeira, poeta-arte-educadora, somando a base teórico-dialógica advinda do mundo das ideias - e da estética -, do pensar sobre a enfermagem.

Quanto aos filósofos e pensadores que se dedicaram à discussão do conhecimento estético, recorreu-se, para produção deste trabalho, a nomes marcantes desde as raízes greco-romanas - Aristóteles, Platão, Plotino - até aquele que representa a visão clássica de estética: o filósofo Kant (Bastos, 1987). Também analisaram estudos de educadores que discutem a importância da estética no campo educacional (Alves, 2000; Goldschmidt, 2004; Maia, 2001). Recorreu-se aos seguintes estudiosos do pensar estético da enfermagem (Horta, 1979; Collieré, 2003; Santos, Gualtier, Figueredo, Petit, 2005; Siles González, 2014; Siles González, Solano Ruiz, 2011).

Abrasileirando o pensar estético, amparou-se no pensar de Alves (2001), que existe um mundo sensível e estético nascido de sonhos. Quanto à fundamentação poética, houve diálogo com as vozes líricas da literatura poética brasileira: Cecília Meireles (1973) e Carlos Drummond de Andrade (1974), que permitiram a autora retomar ao papel sagrado da poesia no campo do conhecimento. Ou seja, para concepção deste trabalho científico tentou-se o exercício dialógico entre vários campos do saber, envolvendo a ciência e o mundo de sonhos estéticos e de muita subjetividade, o que ocorreu no mundo real fruto de complexidade

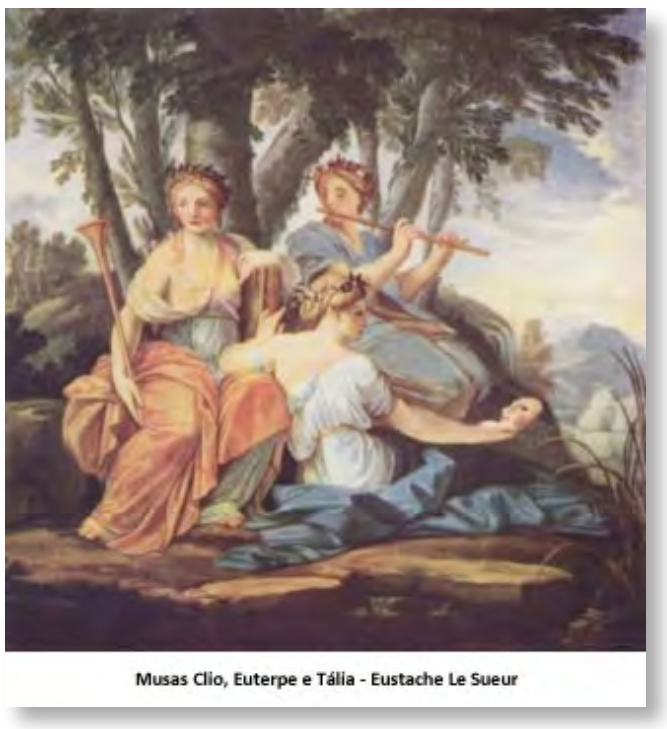

(Morin,1990).

A autora foi inquietada pelas perguntas que soavam entre os acordes líricos: qual a importância da poesia para a enfermagem referenciada como ciência e arte? Quanto ao cuidado integral, há lugar para o conhecimento estético, a despeito de o mesmo ser pouco pesquisado? Sim, pensava, porque existe o lugar sagrado, considerando que o Ser-Enfermeiro tem o potencial criador, assim como o Ser-Cuidado, ambos trocam energia, revitalizam-se continuamente (Rogers, 1970). Esta troca energética vital entre as pessoas que interagem no cuidado - o enfermeiro e aquele que recebe o cuidado - tem caráter humano e humanístico, trata-se de relação de natureza estética, incluindo sonhos, subjetividades e a liricidade oriunda da arte poética que está na vida.

Assim, aconteceu com a presente reflexão oriunda das discussões inspiradoras sobre a produção do saber durante uma disciplina acadêmica. A concepção do estudo foi delineada a partir de versos e estrofes, um sonho bom que surgiu no despertar do eu-lírico, nas aulas, em tardes primaveris. Ou seja, o ambiente gestatório do saber foi numa sociedade de saber, 
na disciplina Cuidado de Enfermagem no desenvolvimento humano - obrigatória dentro do currículo do Programa de Pós-graduação em Enfermagem (PPGENF), da Universidade de Brasília.

No início da disciplina, realizou-se um passeio histórico-reflexivo do processo de construção e desenvolvimento científico que motivou alguns filósofos e cientistas. Os atores educacionais reunidos - docentes e discentes discutiram sobre os protagonistas que sonharam em prol da ciência, desenvolvendo estudos, referenciais teóricos, teorias, nas distintas áreas do saber.

Durante a disciplina, em especial, refletiu-se sobre a vida de Giordano Bruno a qual ilustra a sua obstinação na defesa de suas ideias, sonhos e teorias, em contexto histórico marcado pelo embate entre a ciência e a religião frente ao desenvolvimento científico. Estas análises e reflexões contribuíram para entender a história da construção do conhecimento de enfermagem. Por longos anos, a profissão enclausurou-se no saber técnico do modelo tecnicista, preocupado no fazer e fragmentação - impedindo o ensino e exercício profissional crítico, criativo e político.

No final da década de 1970, segundo Tomey (2004) foram identificados por Carper quatro padrões do conhecimento de enfermagem: 1) empírico (ciência da enfermagem); 2) estético (arte da enfermagem); 3)moral (ética da enfermagem); 4) pessoal (uso terapêutico de si mesmo). Vale et al (2009) acrescentam que no Brasil identificaram outros conhecimentos de enfermagem: histórico, técnico, humanístico e sócio-político.

Particularmente na análise desta autora, observou-se que a disciplina cursada tornou-se espaço de estímulo e desenvolvimento da sua criatividade, amparando-se no dizer de Castanho (2000) que o ensino superior pode fomentar atividades visando a formação de pessoas com autonomia intelectual, apaixonados pela busca do saber e que demonstrem atitudes positivas - em visão prospectiva, estes profissionais, uma vez egressos das suas áreas de formação, desempenharão papéis com relevância social. Corroborando no mesmo entendimento de Castanho (2000), para Vale et al (2009) a práxis em Enfermagem se constrói libertadora, solidária, emancipatória pelo entrelaçamento de saberes e fazeres do cuidado que converge em ciência, ética, arte e estética.

A enfermagem atual enfatiza que é na práxis dialógica e libertadora, oriunda de situações complexas, que os novos caminhos são construídos. Quanto ao conhecimento estético, este pode ser produzido no campo de formação sendo momento singular de desenvolvimento de habilidades expressivas, criativas, comunicativas, lúdicas, por exemplo.

O caminho da enfermagem na dimensão integral está voltado à ciência e à arte. Quanto à experiência, esta autora há algum tempo atua com reflexão do saber poético, coordena projetos sobre a criatividade e ludicidade, produz e pesquisa o conhecimento estético da profissão do cuidar (Silva,1986,1990,1998,2001,2010,2011).

Este trabalho enfatizará a necessidade da produção do conhecimento estético da enfermagem, frente ao mundo atual inserido na aura da complexidade (Capra,1990; Morin, 1990).

Da fruição poética, a autora, sendo Ser-Enfermeira de natureza política e social, produziu diversos textos poéticos, dentre estes, analisaremos o poema a seguir:

\section{$\mathrm{Na}$ argila poética, as minhas reflexões sobre a ciência dos cuidados}

Ano novo me chamando para reflexão

A necessária ressignificação

Tal qual a argila pelo oleiro trabalhada 
Criada, re-criada, em constante transformação.

Em roda, praticando a dialogicidade

Doravante, em constante análise e pensar,

Sobre a vida, o mundo, a profissão,

Sobre o processo aprender e ensinar

Sobre a práxis refletida, em dialética.

Dias de construção da minha essência

Dias de reflexão sobre a transcendência

Da prática Enfermagem e o mundo da ciência.

Vivencio neste caminho de construção

O processo também de desconstrução

Que precisa dos seguintes elementos:

Argila, água, cuidado, emoção.

Muito se desvelou nas minhas memórias

Canal aberto para aprender a aprender:

Sobre Filosofia, constructos e ciência,

Saberes, práticas e conceitos a rever.

Epistemologia? Eu tenho que entender

E também algumas diferenças:

Cuidado, cuidados e assistência.

Figuras relacionadas à argila originam-se das minhas mãos

Pelo significado da mesma nesta aprendizagem

Quando Ayres fala sobre cuidado e reconstrução

Concordo, plenamente com a comparação:

O Ser é tal qual a argila que antes da modelagem

Precisa atravessar o rio atrás da sua identidade

Durante a vida, seu eterno processo de construção.

Por isso, vou vivendo e construindo os meus dias

Na relação eu-tu, mix de diálogo e alteridade

Com minha família, meus pares, professores

E uma diversidade de irmãos e atores.

Hoje quero ser cuidada das minhas dores

Quero também produzir cuidado de enfermagem

Usando a ciência-arte e muita subjetividade

Moldando o meu self na argila, com criatividade

Busco a minha essência, no horizonte, eterna viagem,

Busco infinitas possibilidades e muitas cores

"Para não dizer que não falei das flores".
Do sonho ao despertamento do eu-lírico, a experiência vivenciada pela protagonista deste artigo foi singular e transformadora. Além dos poemas produzidos, surgiu a proposição deste trabalho, que é um relato sistematizado da experiência de construção do conhecimento estético em enfermagem, mediado pela inspiração poética e pela Teoria da Complexidade.

\section{REFLETINDO SOBRE AS FONTES DO SA- BER ESTÉTICO E O CUIDADO}

Há escassez de estudos sobre criatividade para o ensino superior - conforme estudos de Alencar (1995, 1997). Silva e Alencar (2003) apresentaram contribuições importantes na investigação do fenômeno criatividade no ensino de graduação em enfermagem, discutindo as barreiras neste nível de ensino para o desenvolvimento do potencial e subjetividades dos docentes e discentes.

Maia (2001), na direção das autoras acima, também apontou que a escola tolhe a imaginação criativa dos jovens, focalizando no estudo a importância menor às artes, às atividades recreativas e ao texto poético. Ela reportou à história sobre a existência do homem integral na Grécia antiga. Ou seja, o homem integral era aquele que se envolvia com as artes, a poesia, realizava rupturas internas para sair da caverna, observando e interagindo com o mundo exterior.

Em complemento, ressalta-se a abordagem de Goldschmidt (2004) sobre a educação como experiência estética. Para desenvolver seu estudo, ela fundamentou em conceitos da antropologia, sociologia e da filosofia com reflexão aprofundada entre arte e educação.

Referente ao campo da Enfermagem, analisando o paradigma educacional vigente, o currículo expresso nas Diretrizes Curriculares Nacionais para o Curso de Enfermagem

${ }^{1}$ A inspiração para este poema emergiu das reflexões da disciplina "Cuidado de enfermagem no processo do desenvolvimento humano", no $2^{\circ}$ semestre de 2011, oferecida pelo Programa de Pós-graduação em enfermagem-UnB. 
(DCN) destaca aspectos importantes na mudança paradigmática da formação do enfermeiro: as metodologias ativas, o estudante como ator, a ênfase nas habilidades incluindo a comunicação (Brasil, 2001).

Mas de fato as habilidades de comunicação são trabalhadas no espaço curricular? Os textos produzidos valorizam todos os padrões do saber, incluindo o estético? Quanto à comunicação, há espaço curricular para a valorização e construção de texto poético pelos atores sociais da enfermagem - docentes e discentes -, considerando-o como produção de conhecimento?

Na obra A Educação do ser poético, o escritor Drummond (1974) abordou o desprestígio dos textos poéticos na escola, levantando vários questionamentos: Por que motivo as crianças de modo geral são poetas e, com o tempo, deixam de sê-lo? Não se trata, portanto, de que a escola assuma a responsabilidade de "fazer poetas", mas de desenvolver no aluno (leitor) sua habilidade para sentir a poesia, apreciar o texto literário, sensibilizar-se para a comunicação através do poético e usufruir da poesia como uma forma de comunicação com o mundo.

Outra autora reflete que "à medida que as crianças crescem, elas estudam a poesia de uma maneira menos intensa ou de uma forma mais técnica, e as atividades lúdicas vão ficando cada vez mais raras, assumindo o controle a tendência racionalizante" (Maia, 2001, p.17).

O campo da enfermagem também vivencia este lado positivista, hegemônico e que enfatiza a racionalidade. Infelizmente a profissão ainda está voltada para o modelo educacional tecnicista - impedindo aos profissionais desenvolverem o potencial criativo, incluindo o poético.

Quando Carper identificou quatro padrões fundamentais do conhecimento de enfermagem - dentre estes o estético, a arte da enfermagem (Tomey, 2004) -, no mesmo período surge o conceito brasileiro de enfermagem: " $a$ ciência e a arte de assistir ao ser humano (indivíduo, família e comunidade), no atendimento de suas necessidades básicas; de torná-lo independente desta assistência, quando possível, pelo ensino do autocuidado, de recuperar, manter e promover sua saúde em colaboração com outros profissionais" (Horta, 1979).

Mas, no contexto científico, pouco se observa a produção estética da enfermagem. Estudiosos têm discutido a prioridade ao conhecimento empírico e técnico em relação ao estético (Collieré, 2003; Santos, Gualtier, Figueredo, Petit, 2005; Siles González, 2014; Silva, 2001, 2003, 2010).

Muitos caminhos ainda a trilhar em prol do conhecimento estético, da multidimensionalidade, conectividade e outros conceitos da Teoria da Complexidade (Morin, 1990) - elementos importantes na modelagem da arte poética, da criatividade e da subjetividade do profissional.

Por exemplo, sendo de natureza subjetiva, é impossível a pessoa viver, conviver ou interagir sem a criatividade; sendo possível aumentar o número de pessoas quanto as suas potencialidades criativas, expressivas, estéticas, líricas (Assmann,1988; Csikszentmihalyi,1996). Esta afirmativa também se refere à Enfermagem, cujo objeto nuclear é a ação cuidativa - atividades relacionadas ao potencial criativo refletem no cuidado integral. Justamente no contexto educacional que esta autora experienciou a aprendizagem significativa. Como protagonista da construção do seu conhecimento, foi em roda e dialogicidade que a mente criadora da autora-poeta foi despertada pelo eu-lírico. Como Ser-Enfermeira ela transformou-se no processo (Bordenave, 1980), desmistificando e ressignificando seu saber, construindo o material poético deste estudo. 
Neste século em que se propaga o discurso da inter e transdisciplinaridade, dentre as incoerências é que pouco se analisa a poesia como fonte de conhecimento. Vale destacar o filme histórico no século XX - A Sociedade dos Poetas Mortos (Schulman, 1989) -, que abriu ampla discussão sobre este problema, ou seja, a ênfase no ensino rígido, normativo e repressor, em detrimento da educação que valoriza as potencialidades estudantis. Este filme abordou a importância da arte sensível que gera o saber estético, a autonomia e a independência.

Precisamos de poesia para desenvolver o conhecimento estético da enfermagem? Qual a importância da poesia, ou como já denunciou Drummond, ela é vivida apenas pelas crianças? Será que a arte poética desapareceu do homem feito? - neste artigo trata do Ser-enfermeiro.

Este trabalho propõe analisar a poesia na enfermagem e refletir onde estão as sociedades que congregam aqueles que constroem o conhecimento estético em prol do cuidado integral. Objetivou-se, portanto, refletir e analisar a importância do texto poético para produção do conhecimento estético de enfermagem, utilizando como instrumento de análise um poema produzido pelo eu-lírico de uma enfermeira, baseando na Teoria da Complexidade.

\section{METODOLOGIA}

Apresenta-se neste estudo o relato de uma doutoranda em enfermagem cuja experiência foi o despertar do eu-lírico, que emergiu das reflexões individuais e coletivas. Da experiência estética foram produzidos textos poéticos, reflexivos e críticos, frutos da ressignificação do seu saber, visando contribuir na produção do conhecimento estético da enfermagem.

Referente à disciplina cursada - Cuidado de Enfermagem no desenvolvimento humano -, é

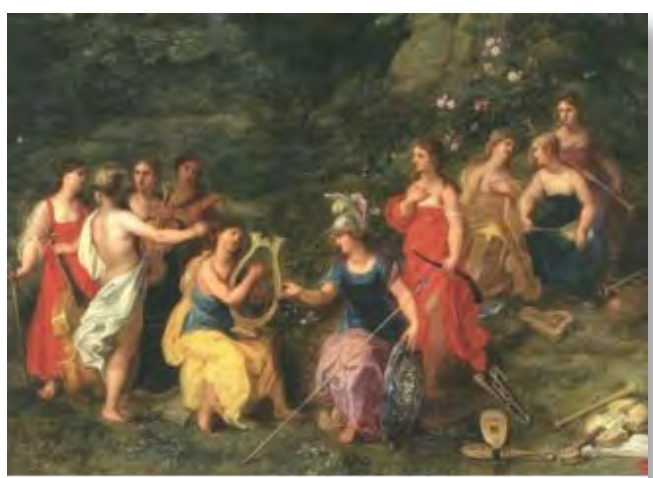

Musas - Minerva Among The Muses

obrigatória no PPGENF, Universidade de Brasília-Brasil. Trata-se de uma disciplina que aborda a construção do conhecimento como fundamental para o desenvolvimento humano e da profissão. Oferece as bases para compreender o corpo saber da enfermagem que estrutura a ciência do cuidado e o objeto da prática; propicia a reflexão crítica do saber e das abordagens metodológicas da prática e a pesquisa de enfermagem (Pinho, Jesus, Reis, Kamada, 2011).

Sobre a metodologia, na disciplina utilizaram as seguintes estratégias: aulas expositivas; discussão de artigos científicos e textos; seminários, estudos individuais e coletivos. No programa foram apresentadas referências básicas para ampliar a rede de conhecimento. Sendo protagonista na construção do seu saber, a autora, além da proposta acadêmica, mergulhou em outras fontes como: história da enfermagem, literatura poética, músicas e filmes. No processo de ação-reflexão-ação ocorreu o despertar do eu-lírico da autora. Ou seja, foram vivenciados os saberes construídos, desconstruídos e reconstruídos no processo reflexão-ação (Freire,1996).

Partindo do princípio de valorizar o despertar do eu-lírico, a autora dialogou com o mundo interior e exterior, materializando a liricidade vivida. As poesias crítico-reflexivas foram recitadas perante o grupo; sendo distri- 
buído o texto poético e publicado no moodle da disciplina.

Para construir este trabalho, o material de pesquisa foi tratado de maneira reflexiva e sistemática, apreendendo os significados da estética, relacionando enfermagem e o poema produzido. Inspirou-se, principalmente, nas poesias de linha filosófico-existencial compostas por Cecília Meireles e Drummond. Posteriormente, o poema de autoria desta protagonista e selecionado para compor o presente estudo, foi analisado à luz da Teoria da Complexidade.

\section{RESULTADOS E DISCUSSÃO}

Foram analisadas referências das seguintes áreas do saber: enfermagem, filosofia, educação, sociologia, literatura, poesia e filme. $\mathrm{Na}$ análise baseou-se em alguns conceitos estruturantes.

\section{Conceitos estruturantes: poesia, estética, co- nhecimento estético}

Visando analisar o poema e elaborar a reflexão junto aos artigos selecionados, fundamentou-se em alguns conceitos relativos à temática do conhecimento estético e a Teoria da Complexidade.

Os conceitos explorados foram poesia, estética e complexidade.

Ao conceituar poesia, reportou-se à clássica obra de Aristóteles - a Poética -, pois este filósofo considerava a arte como poíesis, criação, ato de produzir, plasmar, organizar, configurar na realidade algo novo, um outro Ser (Sousa, 1966; Bastos, 1987). Assim a poesia tem definição ampla, não está restrita ao poema, mas também em paisagens, objetos e formas expressivas como culto, divertimento, jogo, ensinamento, relações humanas (Huizinga, 1996). Entende-se assim que poesia é a substância imaterial e o caráter do que emociona, toca a sensibilidade e sugere emoções por meio de uma linguagem; poema é a obra em verso em que há poesia, é produto empírico, tem existência concreta e usa palavras como matéria-prima. O poema destaca-se pelo modo como se dispõe na página. Cada verso tem um ritmo específico e ocupa uma linha. O conjunto de versos forma uma estrofe e a rima pode surgir no interior dessa estrofe.

Quanto à expressão estética, é um termo que vem sendo utilizado desde a Antiguidade, mas atualmente com outro significado. Refere-se, de modo geral, à ciência ou à teoria do Belo. Entre os gregos usava-se o termo poética (poíesis) no sentido de criação e fabricação sendo aplicado à poesia e outras artes. Depois a estética passou a abranger toda a reflexão filosófica que tem por objeto as artes. A palavra estética vem do grego aisthesis, que significa ação genérica de sentir, à sensação, ao conhecimento sensorial ou sensibilidade - foi adotada pelo filósofo alemão Alexander Baumgarten (1714-1762) para nomear o estudo das obras de arte como criação da sensibilidade, tendo por finalidade o belo. $\mathrm{Ou}$ seja, engloba tanto o estudo dos objetos artísticos - conforme seu modo singular e sensível - quanto pelos efeitos que estes provocam no observador cujos significados só podem ser percebidos por meio da experiência estética - ou seja, o sentimento que ele suscita nos homens (Bastos, 1987).

Em relação à Teoria da Complexidade chamada de desafio ou pensamento da complexidade -, é uma visão interdisciplinar dos sistemas complexos adaptativos, do comportamento emergente dos sistemas, da complexidade de redes, da teoria do caos, do comportamento dos sistemas distanciados do equilíbrio termodinâmico e das faculdades de auto-organização (Morin, 1990). 


\section{A personalidade criativa e as dimensões da complexidade}

Para análise do conhecimento estético da enfermagem, fez-se necessário recorrer aos fundamentos sobre a personalidade criativa inerente aos poetas, artistas, filósofos e outras personalidades que utilizam da subjetividade para produzir as suas construções estéticas.

Segundo arrazoados de Amabile (1983), Arieti (1976), Csikszentmihalyi (1992, 1996), Martinez (1997) e Renzulli (1992), as pessoas podem tornar mais criativos, influenciados por fatores extrínsecos como: experiências criativas no sistema família-escola, ambiente adequado para reforçar os traços de personalidade, as dimensões da complexidade e demais atributos. Csikszentmihalyi (1996) revela três definições: a pessoa brilhante expressa pensamentos inusitados e estimulantes; a personalidade criativa refere-se às pessoas de percepção tranquila e cheias de insight; e pessoas criativas as que mudam a cultura com realizações notáveis.

Segundo Csikszentmihalyi (1996), as pessoas criativas possuem pelo menos dez dimensões da complexidade: 1-possuem grande energia psíquica em um polo e tranquilidade noutro polo;2-são simultaneamente inteligentes e simples; 3-combinam brincadeira e disciplina, responsabilidade e irresponsabilidade; 4-alternam imaginação e fantasia necessárias para sentir o presente sem perder o toque do passado; 5-apresentam traços de introversão $e$ extroversão; 6-apresentam-se como humildes/ arrogantes, ambiciosos/altruístas, competitivos/ cooperadores; 7- são cuidadosos, sensíveis e rígidos, dominantes e submissos; 8-são rebeldes e independentes; 9-são passionais e objetivos nos trabalhos; 10-apresenta liberdade e sensibilidade, angústia e sofrimento seguidas de prazer $e$ divertimento.
Análise do poema $\mathrm{Na}$ argila poética, as minhas reflexões sobre a ciência dos cuidados

Para estudo sistemático do poema $\mathrm{Na}$ argila poética, as minhas reflexões sobre a ciência dos cuidados, o mesmo pode ser comparado à linha de produção literária de Cecília Meireles e Drummond, haja vista que a autora também trabalhou a linha filosófica e existencial trilhada por estes dois poetas ilustres, representantes da arte de poetar brasileira.

Cecília Meireles cultivou uma poesia reflexiva, de fundo filosófico, que aborda, entre outros, temas como a transitoriedade da vida, o tempo, o amor, o infinito, a natureza, a criação artística. Drummond representa a segunda geração de modernistas, pela poesia do questionamento da existência humana, do sentimento de "estar-no-mundo", das inquietações social, religiosa, filosófica, amorosa (Cereja, 1999). Sem dúvida que algumas obras destes notáveis poetas contêm os princípios da Teoria da Complexidade de Edgar Morin.

Quanto ao poema básico, instrumento de análise deste estudo, também foi analisado e será discutido adiante considerando aspectos de estrutura poética - contém o título, 41 versos, quatro estrofes e rimas - relacionando-o às referências estudadas e à luz da Complexidade.

\section{Análise da primeira estrofe}

Na primeira estrofe, composta de doze versos, observa-se a inquietação do eu-lírico filosófico e existencial da poeta despertado para o exercício de ação-reflexão-ação. A autora coloca-se como protagonista no chamamento lírico, refletindo a própria prática profissional. Mostra que a reflexão além do exercício interno e individual é também de natureza coletiva, "em roda e dialogicidade".

Ano novo me chamando para reflexão / A necessária ressignificação / Tal qual a argila 
pelo oleiro trabalhada / Criada, re-criada, em constante transformação / Em roda, praticando a dialogicidade / Doravante, em constante análise e pensar, / Sobre a vida, o mundo, a profissão,/ Sobre o processo aprender e ensinar / Sobre a práxis refletida, em dialética. / Dias de construção da minha essência/ Dias de reflexão sobre a transcendência / Da prática Enfermagem e o mundo da ciência.

Para fundamentar a estrofe acima, como o poema foi elaborado no contexto educacional, é importante destacar que a aprendizagem significativa, individual, mútua e coletiva promove e produz sentidos nos espaços dialógicos (Merhy, 2012). Sendo sujeito desta construção conceitual, a autora vivenciou a máxima de Bordenave (1980,p.10) "uma pessoa só conhece bem algo quando transforma, transformando-se também ela no processo". Este ideário de educação, libertador, é próprio do cuidar que se estabelece na parceria, comunhão, relações subjetivas, mesclada com sonhos, dores, alegrias e das emoções inerentes à complexidade.

Os encontros acadêmicos são espaços de aprendizagem significativa, contrariando os estudos que consideram que no nível superior não há lugar para a criatividade. Estes encontros devem oferecer atividades para desenvolvimento de habilidades de comunicação, como a produção da arte poética e estética, corroborando ao pensar de Drummond (1974) e Maia (2001).

Importante destacar uma cena do filme A Sociedade dos Poetas Mortos (Schulman, 1989), na qual o professor John Keating provoca os estudantes para alterar a dinâmica da aula de modo que eles enxergassem a sala com outro olhar e novo ângulo. A partir daquela experiência os estudantes são incentivados para gostar de poesia, despertando a autonomia dos alunos para escrever as suas ideias e sentimentos profundos, levando-os à visão crítica da sociedade vivida. Foi um exemplo claro de estímulo do conhecimento estético mediado pela poesia.

$\mathrm{Na}$ estrutura do texto poético $\mathrm{Na}$ argila poética, as minhas reflexões sobre a ciência dos cuidados, concebido em espaço acadêmico, aborda acerca de sonhos, subjetividades, diálogo, escuta qualificada, toque e dialogicidade. Os atores de ambiente acadêmico podem contribuir na produção do saber, pois são sujeitos do vivido, do pensar crítico e prática refletida.

A autora abriu o seu campo de complexidade, e no mundo real da disciplina fonte do poema, vivenciou a roda dialógica, na qual deparou com a essência de si mesma e suas potencialidades. Como protagonista do seu saber, retornou ao húmus, à argila poética, à sua essência poiésis, tornando-se livre para poetar, criar, recriar, modelar, construir e reconstruir o saber, movimento inato do poeta na acepção de Aristóteles (Bastos, 1987; Sousa, 1966, Huizinga, 1996).

A disciplina como canal de fruição poética permitiu à autora relacionar a obra poética ao conhecimento estético, assentado no conceito de cuidado como "... uma interação entre dois ou mais sujeitos visando o alívio de um sofrimento ou o alcance de um bem-estar, sempre mediada por saberes especificamente voltados para essa finalidade" (Ayres, 2004, p.74).

O estudo de Vale et al (2009) avança além história de teor científico, para a reflexão sobre os saberes e práxis em Enfermagem. Em suas reflexões, apontam a visão atual e inovadora do conhecimento ao desfazer as certezas, vendo o saber de modo global, com características dinâmicas, delimitadas pelo movimento de "desconstrução" e "construção". Desconstrução não vista como algo aniquilador, mas processo contínuo de aprendizagem.

Sobre a práxis, Vale et al (2009) apresentam definição do ser humano na dimensão global e que se autoproduz pela dialética. Importante 
destacar também que a práxis em Enfermagem se constrói libertadora, solidária, emancipatória pelo entrelaçamento de saberes e fazeres do cuidado que converge em ciência, ética, arte e estética. É nessa práxis que coexistem situações complexas, adversas e conquistas que os novos caminhos para a Enfermagem são construídos.

\section{Análise da segunda estrofe}

Ao ser analisada a segunda estrofe, composta por onze versos, o conhecimento estético de enfermagem enfatiza as subjetividades necessárias para o encontro relacional entre o Ser-profissional que realiza o cuidado e o Ser que recebe o cuidado.

Vivencio neste caminho de construção / O processo também de desconstrução / Que precisa dos seguintes elementos: / Argila, água, cuidado, emoção. / Muito se desvelou nas minhas memórias / Canal aberto para aprender a aprender: / Sobre Filosofia, constructos e ciência, / Saberes, práticas e conceitos a rever. / Epistemologia? Eu tenho que entender / E Também algumas diferenças: / Cuidado, cuidados e assistência.

\section{Elementos necessários para a modelagem do cuidado estético}

A segunda estrofe é desenvolvida em movimento singular, mesclando a fruição poética com termos e conceitos essenciais para gerar conhecimento na base estética. São referenciados elementos da base subjetiva como a argila, a água, o cuidado e emoção - estes elementos oriundos da natureza poética têm a energia, o movimento que auxilia na modelagem, construção e reconstrução humana. Aristóteles já mostrava a natureza humana complexa, modelada na arte poética - sua obra Poética é fundamental para entender a concepção estética.

Fazendo correlação com a ciência e arte enfermagem definida por Horta (1979), esta teó-

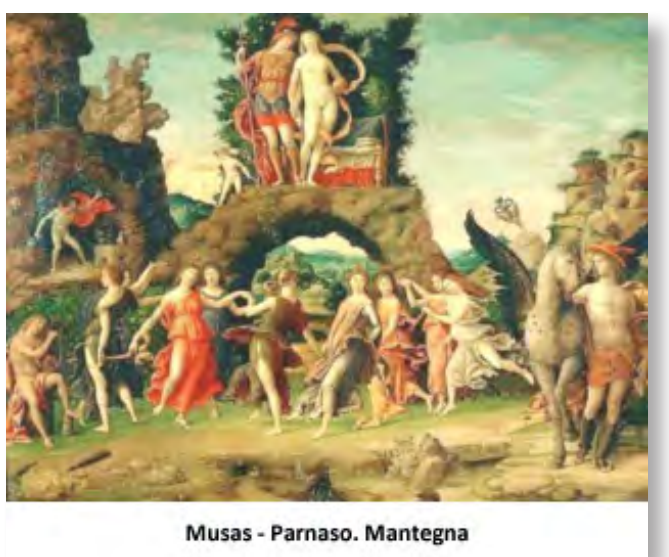

rica recorre ao pensamento estético, inovando a assistência ao ser humano (indivíduo, família e comunidade), via sensibilidade com vistas ao atendimento de suas necessidades básicas.

Ainda na segunda estrofe, também emerge o pensamento estético e complexo autoral, fundada na abordagem transdisciplinar dos fenômenos, poetando sobre a mudança de paradigma, explorando a criatividade e também o caos, quando fala da construção e desconstrução.

Para atuar na enfermagem os profissionais precisam de vários conhecimentos frente às situações complexas (Brasil, 2001). Assim, o profissional, para alcançar este perfil, precisa recorrer à sua essência subjetiva, passar pela modelagem da argila, construir-se e reconstruir-se diariamente para desenvolver o cuidado, estimular as potencialidades, trabalhar as emoções, deixar-se conduzir pelo despertar do eu-lírico, pela fluência e movimento das águas que revitalizam e energizam o ser humano, porque Conhecer melhor para melhor cuidar é reencontrar o sentido original do conhecimento; conhecer é nascer com o que descobrimos [...] e com o que aprendemos[..]. O conhecimento é uma dinâmica permanente daquilo que nos faz nascer cada vez mais para a vida. Os cuidados são fontes de conhecimento (Colliére, 2003, p.112). 
Há riqueza da história dos saberes e dos cuidados. Para Colliére (2003) os cuidados foram criados, inovados e gerados pelo saber. Ela define "ciência dos cuidados" no lugar de "ciência de enfermagem" - reportando-se à gênese, evolução e a involução dos saberes da prática do cuidar. Defende que os cuidados não pertencem aos enfermeiros, mas a cada pessoa para assegurar a própria sobrevivência. De igual modo, Siles González e Solano Ruiz (2011) contribuem com estudo referente à história cultural e a estética dos cuidados de enfermagem, objetivando esclarecer o papel da estética na organização e motivação dos cuidados na história.

Destaca-se a reflexão de Colliére (2003) que os cuidados foram os cuidadores do saber, surgindo depois os saberes científicos desvalorizando os saberes natos, pelo rigor acadêmico. Segundo ela, no final da Idade Média o saber das pessoas letradas era valorizado, e o saber das não letradas era inferiorizado, objeto de desconfiança e condenação. Séculos depois, a própria ciência muda tal ordem e os saberes empíricos passam a ser investigados nas academias, por meio da antropologia e história oral o estudo de Siles González e Solano Ruiz (2011) corrobora de forma substancial na análise desta trajetória histórica dos cuidados e estética.

Atualmente observa-se a supervalorização dos saberes científicos e as tentativas de valorizar os populares. Neste tópico, Colliére (2003) reflete acerca da fragilidade da enfermagem; ou seja, a luta para construir o próprio saber, pois na questão científica o corpus doutrinae da profissão é oriundo geralmente de outras áreas. Ela destaca que o mundo dos cuidados tem riquezas, nuanças, desejos e cheio de subjetividades - por ser feito da essência humana -, por isso, não cabe os ditames científicos, pois os usuários são sujeitos deste vivido, desta prática milenar.

\section{Análise da terceira estrofe}

$\mathrm{Na}$ terceira estrofe, que apresenta sete versos sonoros, a enfermeira-poeta mostra o processo de como a poesia foi construída dentro da modelagem estética. Novamente, utiliza o elemento da natureza - a argila poética - enfatizando este elemento que molda e faz moldar, constrói e reconstrói o aprender estético. No espelho da própria poesia, vê refletida sua autoimagem, identidade e subjetividades. Em síntese, mostra o encontro da sua essência, enquanto ser-enfermeira-poeta.

Figuras relacionadas à argila originam-se das minhas mãos / Pelo significado da mesma nesta aprendizagem / Quando Ayres fala sobre cuidado e reconstrução / Concordo, plenamente com a comparação: / O Ser é tal qual a argila que antes da modelagem / Precisa atravessar o rio atrás da sua identidade / Durante a vida, seu eterno processo de construção.

Nesta análise recorreu-se ao conceito de poesia defendido por Aristóteles e Huizinga como modelagem estética. Também fundamentou-se em Ayres (2005) como referencial ímpar pelas concepções, significados e enfoque da alegoria do Cuidado, oriundo da argila - este artigo contribuiu na ideia do poema, pela metáfora da argila, ancorando os significados e conceitos relacionados à ciência em enfermagem.

No processo de teorização sobre desenvolvimento do conhecimento, o conceito do Cuidado foi bastante significativo, pois ele sendo a "argila”, também é o primeiro, é o amálgama e o seu movimento chama à existência os demais. Ayres (2005) examina o Cuidado sob três categorias conceituais: ontológica, genealógica e crítica.

Destaca-se o seguinte conceito de cuidado como uma categoria que suscita a alteridade pelo movimento ativo de profissionais e serviços de saúde, até a presença do outro, promoven- 


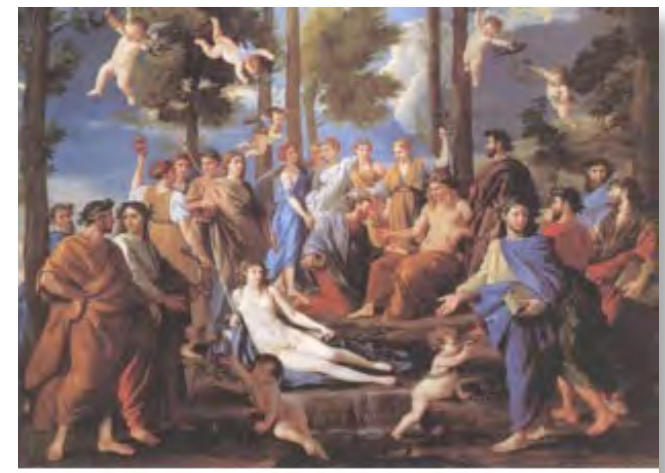

Musas - Paranaso - Poussin

do a otimização, a diversificação e a qualidade na interação eu-outro, além da ampliação dos saberes e fazeres em saúde na perspectiva interdisciplinar e intersetorial (Ayres, 2004,2005).

Sem dúvida que a produção do cuidado extrapola o ato técnico - centrado em procedimentos - sendo a ênfase as dimensões subjetivas que orientam a ação cuidativa integral: arte em todas as linguagens e gêneros estéticos, humanização, integralidade, equidade, acolhimento, vinculo, interrelação, interação, confiança, dignidade, espiritualidade, solidariedade, alteridade, carinho, confiança, responsabilidade e corresponsabilidade, ética, saber e prática compartilhados, práxis, pluralidade dialógica e inúmeros aspectos que envolvem a dimensão complexa (Ayres, 2004, Colliére, 2003; Siles González, 2014; Siles González e Solano Ruiz, 2011).

Por isso, cuidado é a alma dos serviços de saúde, como bem definiu Merhy (2012). Todas estas características fornecem rico material para a inspiração e fabricação de poesias líricas, críticas, estéticas; incorporando, sem dúvida, o texto poético ao conhecimento estético da enfermagem.

Ressalta-se a importância da sociopoética como método de construção coletiva do conhecimento reconhecendo as pessoas como corresponsáveis pelos saberes produzidos (Santos, Gualtier, Figueredo, Petit, 2005).
Como estudioso da sociopoética relacionada à estética dos cuidados, Siles González (2014) a considera como uma ponte entre a ciência e a arte, na medida em que a mesma permite o desenvolvimento das dimensões subjetivas, intersubjetivas e complexas, e para emergir elementos estéticos do cuidado: a poesia, a criatividade, a intuição, a sensibilidade, as emoções e toda a riqueza inerente ao universo expressivo humano.

\section{Análise da quarta estrofe}

A quarta e última estrofe do poema é composta por onze versos, cantados liricamente sobre o mundo real, complexo, intrínseco e extrínseco da autora. Ao relacioná-lo à base do conhecimento estético, emerge a tríade: cuidado ciência, cuidado do outro e o cuidado de si.

A poeta-protagonista como pesquisadora e profissional revela a sua essência humana, o seu eu-lírico no compasso sonoro da arte, das relações diversas que podem ser estabelecidas, em dialogicidade. A última estrofe refere-se ao mundo da complexidade, que é constituído de diversidade, subjetividade, infinitas possibilidades, em constante movimento no mundo dinâmico que se torna uma eterna viagem que só faz sentido para a autora esta viagem ser trilhada de modo estético, com poesia, criatividade, cores e flores.

Por isso, vou vivendo e construindo os meus dias / Na relação eu-tu, mix de diálogo e alteridade / Com minha família, meus pares, professores / E uma diversidade de irmãos e atores. / Hoje quero ser cuidada das minhas dores / Quero também produzir cuidado de enfermagem / Usando a ciência-arte e muita subjetividade / Moldando o meu self na argila, com criatividade / Busco a minha essência, no horizonte, eterna viagem, / Busco infinitas possibilidades e muitas cores / "Para não dizer que não falei das flores". 
Refletindo sobre a prática profissional, na construção do Ser-enfermeiro preocupado com diversos problemas, a questão emblemática do mesmo enquanto sujeito da ação cuidativa, é deparar com as fragilidades e o questionamento do seu papel profissional, em desequilíbrio com o cuidado de si. Assim, ele carece desenvolver o novo olhar - na perspectiva estética - ver o real, não olhando somente o objeto isolado, mas em conectividade: o mundo e as cíclicas mudanças, os sentimentos e sensações que mudam o próprio comportamento (Capra, 1990).

O cuidado de si trata da própria transformação estética do ser enfermeiro, aquele que compreende que a sua prática está relacionada ao seu mundo complexo não linear. O cuidado de si exige a compreensão filosófica e estética subjetiva e intersubjetiva - relacionada às situações de ação terapêutica, à saúde individual, coletiva e das populações (Ayres, 2004).

Importante destacar na análise da quarta estrofe, um estudo (Vieira, Kamada e Alves, 2007) que identificou as percepções de auxiliares de enfermagem, sobre o cuidado de si. Trata-se de um estudo referenciado no Cuidado Transpessoal de Jean Watson. Utilizou-se a releitura da obra "Abaporu", de Tarsila do Amaral, e da análise dos dados emergiram os seguintes resultados: o corpo para além dos cinco sentidos; a existência da ligação corpo-mente-natureza; o direito divino de ser cuidado; a ligação do cuidado com a sua plenitude de ser e viver no mundo.

Wiggins (2008) também favorece a discussão da quarta estrofe pela importância do seu mote: o desafio da mudança na enfermagem. Sua abordagem baseia-se na Ciência da Complexidade que possui características como a não linearidade e a imprevisibilidade. A estudiosa discorre sobre o desenvolvimento científico da enfermagem relacionado ao cuidar flexível, sensível, não linear, não determinista, contendo princípios da complexidade. Propõe a reflexão sobre o sistema de saúde e enfermagem, na dimensão real e complexa. Enfatiza o desafio da mudança a ser vivido pelos enfermeiros, exercendo novos papéis no cuidado via trabalho compartilhado que envolve todos os atores, incluindo o enfermeiro, paciente, família e comunidade.

Assim, no desfecho deste trabalho, defendemos a Teoria da Complexidade - dentro do desafio da mudança pois aborda a prática, reflexão diária e transformação social, contrapondo a visão reducionista do pensar linear e fragmentado. Muitos conceitos que constituem o tecido da Ciência da Complexidade foram identificados no poema analisado, elementos estes que constituem a arte estética e precisam ser desenvolvidos na construção do conhecimento de enfermagem. Dentre os conceitos estão presentes no poema $\mathrm{Na}$ argila poética, a reflexão sobre a ciência dos cuidados: auto-organização, autossemelhança, imprecisão, conectividade, construtivismo, correlação, criticabilidade, dialógica, diversidade, fluxo, paradoxo.

Esta discussão amparou-se nestes conceitos complexos, transdisciplinares, que considera a ciência inacabada. Reportando a Carvalho (2003) que em suas reflexões sobre os constructos epistemológicos destaca a máxima de Moles: "a enfermagem é uma ciência-em-vias-de-se-fazer". Ou seja, ainda há muito a trilhar no conhecimento estético da enfermagem. Um dos caminhos pode ser via arte poética, pela riqueza de elementos estéticos essenciais no cuidado.

\section{CONSIDERAÇÕES FINAIS}

Historicamente, no campo filosófico e estético, filósofos e educadores se dedicaram no campo das artes, viajaram nas asas da imaginação, antes de seus sonhos tornarem-se reais, e 
hoje fatos históricos fundamentam a ciência. $\mathrm{Na}$ enfermagem destacam-se as pioneiras Florence Nightingale e Wanda Horta - a última inovou o conceito de enfermagem como ciência e arte.

Conforme o referencial estudado, o conhecimento estético permite cuidado baseado na criatividade nos vários cenários - educacionais de vários níveis, serviços de saúde instituídos, comunidades, praças, no mundo - considerando os desafios a enfrentar como a atenção integral, pois a cultura de produção de cuidados tem natureza estética e complexa.

A complexidade e suas implicações são as bases do pensar de Morin, que vê o mundo como um todo indissociável e propõe a abordagem multidisciplinar e multirrerefenciada da construção do conhecimento. Neste sentido, transdisciplinar e multirreferenciado também inacabado - ainda há muito a trilhar para alcançar a concepção integral de saúde, fruto da produção científica, oportunizando a fabricação científica que contempla todos os padrões do saber.

Consideramos que o desenvolvimento do conhecimento estético deve ser de tal modo que as dimensões sejam trabalhadas em conectividade, incluindo elementos do tecido da complexidade como a arte poética, criatividade, subjetividade e intersubjetividade do profissional que realiza ações cuidativas singulares. Este é o desafio do conhecimento estético em enfermagem: o olhar mútuo, transdisciplinar, dialógico, em troca de saberes, nos cenários de saúde reais e complexos.

Adotar a Ciência da Complexidade contribui para construção do conhecimento estético de enfermagem em prol do cuidado cultural a ser realizado às pessoas, famílias e populações, utilizando além de técnicas e procedimentos, a subjetividade, sensibilidade e muita poesia.

\section{REFERÊNCIAS}

- Alencar EMLS. (1995) Developing creative abilites at the university level. European Journal for High Ability, 6, 82-90.

- Alencar EMLS. (1997) O estímulo à criatividade no contexto universitário. Psicologia Escolar e Educacional, 1(2-3), 29-37.

- Alves R. (2001) Entre a ciência e a sapiência. O dilema da educação. São Paulo: Edições Loyola.

- Amabile TM. (1993) The social psychology of creativity. New York: Springer-Verlag.

- Andrade CD. (1974) A educação do ser poético. Arte e Educação, ano 3, n.15.

- Arieti S. (1976) Creativity: The magic synthesis. New York: Basic Books.

- Assman H.(1998) Reencantar a educação: rumo à sociedade aprendente. Petrópolis, RJ: Vozes.

- Ayres JRCM. (2004) Cuidado e reconstrução das práticas de Saúde. Comunic., Saúde, Educ., v.8, n.14, p.73-92, set.2003-fev.

- Ayres JRCM. (2005) Cuidado e reconstrução das práticas de saúde. Em Minayo, MCS; Coimbra Jr, CEA (Org).Críticas e Atuantes, Ciências sociais e humanas em saúde na América Latina. Rio de Janeiro: Fiocruz, 2005. Cap 6 (91-108).

- Bastos F. (1987) Panorama das idéias estéticas no ocidente (de Platão a Kant). Brasília: Editora da Universidade de Brasília.

- Bordenave JD, Pereira AM. (1995) Estratégias de ensinoaprendizagem. 15ª ed. Petrópolis: Vozes.

- Brasil. (2001) Resolução CNE/CES. Dispõe sobre as Diretrizes Curriculares Nacionais do Curso de Graduação em Enfermagem. Diário Oficial da União, Brasília, 9 de Novembro de 2001. Seção 1, p. 37.

- Capra F. (1990) O ponto de mutação. Filme baseado na obra The Turning Poin de Fritjof Capra. Direção Bernt Capra. Duração 126 min. Cannes Home Vídeo.

- Carvalho V. (2003) Sobre construtos epistemológicos nas ciências - uma contribuição para a enfermagem. Rev Latino Am Enfermagem 2003 jul-ago; 11(4):420-8.

- Cereja WR. (1990) Português: linguagens: literatura, produção de texto e gramática, volume III. São Paulo: Atual. 
- Csikszentmihalyi M. (1992) A psicologia da felicidade. São Paulo: Saraiva.

- Csikszentmihalyi M. (1996) Creativity: Flow and the psychology of discover and invention. New York: HapperCollins.

- Colliére MF. (2003) Cuidar: a primeira arte da vida. 2a edição, Portugal: Lusociência.

- Freire P. (1996) Pedagogia da autonomia: saberes necessários à prática educativa. São Paulo: Paz e Terra.

- Gardner H. (1970) Art through the Ages. Harcourt: Brace and World.

- Goldschmidt L. (2004) Sonhar, Pensar e Criar: a educação como experiência estética. Rio de Janeiro: Wak.

- Horta W. (1979) Processo de Enfermagem. São Paulo: EPU.

- Huizinga J. (1996) Homo Ludens: o jogo como elemento de uma cultura. São Paulo: Perspectiva.

- Lerroy P. (1972) La Vita di Leonardo da Vinci. A Vida de Leonardo da Vinci. Diretor Renato Castellani, Gênero Drama, Duração 325 min, Itália.

- Maia MAS. (2001) O texto poético: leitura na escola. Maceió: EDUFAL.

- McEwen M, Wills EM. (2009) Bases Teóricas para Enfermagem. Porto Alegre: Artmed.

- Meireles C. (1973) Poesias completas: Viagem/Vaga música. Rio de Janeiro: Civilização Brasileira.

- Merhy EE. (2012) O ato de cuidar: a alma dos serviços de saúde. Disponível em: <http://paginas.terra.com.br/ saude/merhy/textos/Cinaematocuidar.pdf $>$ Acesso em 10 de mar 2014.

- Morin E. (1990) Introdução ao Pensamento Complexo. Lisboa: Instituto Piaget.

- Pinho DLM, Jesus CAC, Reis, PED, Kamada I. (2011) Programa disciplina Cuidado de enfermagem no processo de desenvolvimento humano. Universidade de Brasília.

- Rogers ME. (1970) An introduction to the theoretical basis of nursing. Philadelphia: F.A.Davis Company.

- Santos I, Glautier J, Figueredo NMA, Petit SH. (2005) Prática de pesquisa em ciências humanas e sociais: abordagem sociopoetica. São Paulo: Atheneu.

- Schulman T. (1989) A Sociedade dos Poetas Mortos, dirigido por Peter Weir, EUA: Disney. (vídeo).

- Siles González J, Solano Ruiz MC. (2011) Cultural his- tory and aesthetics of nursing care. Rev. Latino-Am. Enfermagem, Sep.-Oct.;19(5):1096-1105.

- Siles González, J. (2014) El humanismo en enfermería a través de la sociopoética y la antropoética. Cultura de los Cuidados (Edición digital) 18, 38. Disponible en: <http://dx.doi.org/10.7184/cuid.2014.38.01>

- Silva O. (1987) O Sol da Justiça. Goiânia: Gráfica e Editora Primavera.

- Silva O. (1990) Poemas Tragédia e Tum-Trá. In: Outros Poemas, Coletivo de Poetas. Brasília, DF. Volume 3 da Coleção Escriba. (p. 117-118).

- Silva O. (2001) A criatividade no ensino superior de enfermagem à luz dos componentes do processo ensino-aprendizagem: o professor, o aluno e o currículo [dissertação de Mestrado em Educação]. Brasília (DF):Universidade Católica de Brasília.103 f.

- Silva O. (2002) REBEn: Ah! Se todos fossem iguais a você aos 70 anos. Rev Bras Enferm, 55(3), 245-8.

- Silva O. (2010) Miriã, uma Enfermeira Bambambã. São Paulo: Scortecci.

- Silva O; Alencar, EMSL. (2003) Criatividade no ensino de enfermagem-enfoque triádico: professor, aluno, currículo. Rev Bras Enferm, Brasília (DF) nov/ dez;56(6):610-614 .

- Sousa E. (1966) Poética de Aristóteles. Trad. Pref. Introdução. Comentário e apêndice de Eudoro de Sousa. Porto Alegre: Globo.

- Tomey AM, Alligood, MR. (2004) Teóricas de Enfermagem e sua obra: modelos e teorias de enfermagem. 5 edição. Portugal: Lusociências.

- Vale, EG, Pagliuca, LMF, Quirino, RHR. (2009) Saberes e práxis em enfermagem. Esc Anna Nery Rev Enferm jan-mar, 13 (1): 174-180.

- Wiggins, MS. (2008) The Challenge of Change. Em: Lindberg C, Nash S, Lindberg C. On the Edge: nursing in the age of complexity. USA: Plexo Press, (1-22). 